\title{
Challenges of Using Agricultural Solid Wastes as Aggregate in Structural Concrete
}

\author{
Payam Shafigh ${ }^{1}$, Alireza Javadi Pordesari ${ }^{1}$, Ahmad Zaki ${ }^{2 *}$ \\ ${ }^{1}$ Department of Architecture, University of Malaya, Kuala Lumpur, Malaysia \\ ${ }^{2}$ Department of civil engineering, Universitas Muhammadiyah Yogyakarta, Yogyakarta, Indonesia \\ *Corresponding author.Email: ahmad.zaki@umy.ac.id
}

\begin{abstract}
Considering sustainability in all stages of construction engineering is a need to protect environment, preserve natural resources and the earth for our own and future generations. An effective way to mitigate environmental impacts of the construction industry is the use of sustainable materials in construction. Among all types of construction materials, concrete is the most-used material for civil and industrial infrastructures. Therefore, successful production and application of green concrete is vital in the industry. To achieve sustainability in concrete production, there are a lot of efforts of researchers to produce concretes by incorporating wastes and by-product materials as cement and/or aggregate replacement in the concrete mixtures. For the past decades to now researchers are trying to develop sustainable concrete using agricultural solid wastes as the aggregate to produce structural concrete. However, these types of concretes are not practically used in the construction industry. This paper is a brief review on the oil palm shell concrete mixtures and discussed the challenges and barriers of implementing this concrete in the practice.
\end{abstract}

Keywords-agricultural waste, concrete, sustainable material, construction, concrete in practice

\section{INTRODUCTION}

With growing population and urbanization and consequently, development of buildings and infrastructures, sustainability should be a serious concern for governments, developers, designers and owners. It is due to construction industry is using a significant amount of energy and natural resources during construction, post-construction and operation and each local building and infrastructure could affect the environment of the entire world. One of the ways to reduce the negative environmental impact of construction industry is the use of sustainable construction materials. Among all types of construction materials such as concrete, steel, wood, plastic and aluminum, concrete is the most used. Approximately 33 billion metric tons of Portland cement concrete is used annually [1]. For such huge consumption, any small reduction of raw materials in the concrete mixture will significantly reduce the environmental impact of the product.

For tens of years, researchers put lots of efforts to develop sustainable concretes using wastes and by-product materials in concrete mixtures. From these efforts, waste and by-product materials such as silica fume, fly ash (FA) and ground granulated blast-furnace slag (GGBFS) are successfully used in construction industry. These cementitious materials are commonly used as additives or Portland cement replacement in the concrete mixture in low and moderate volumes. However, researchers are still on going to develop mix proportions of concretes containing high-volume FA and. GGBFS. By encouraging the construction industry to use supplementary cementitious materials not only can reduce the usage of Portland cement in concrete, and consequently, reduces the $\mathrm{CO}_{2}$ emission, but also can increase the durability and lifetime of structures $[2,3]$. Extensive researches are on going to develop mix proportions for concretes incorporating cementitious materials origin from agricultural wastes such as rice husk ash, palm oil fuel ash, bagasse ash, wood waste ash, bamboo leaf ash and corn cob ash [4]. Using most of these cementitious materials in concrete are in a lab scale and extensive research on technical and economic aspects are still required to make confident the designers and developers to use these industrial wastes.

Besides of using supplementary cementitious materials in concrete mixtures to reduce the environmental impact of Portland cement concrete; researchers are developing sustainable concrete using solid wastes as an aggregate in concrete mixtures. The global aggregate production from natural resources for construction industry significantly increased from 21 to 40 billion tones just from 2007 to 2014 [5]. Therefore, there is a great opportunity to develop sustainable concrete by replacing a portion of natural aggregate with industrial solid wastes in civil engineering projects. Germany is the first country among the developed economies to initiate minimizing and recycling construction and demolition (C\&D) wastes in 1980 [6]. 
The source of solid wastes to be used in concrete mixtures could be organic (agro-waste), inorganic (industrial waste), mining/mineral, hazardous and non-hazardous [7]. The C\&D wastes are the most type of recycled aggregates, which practically used in concrete production. However, there are also solid wastes in the agricultural sector which could be used as an aggregate in concrete [8]. Although, there are many researchers to develop application of agricultural solid wastes in concrete production, however, the application of these materials is not yet in the industrial scale. This paper is a discussion about the barriers facing application of an agrowaste material, namely oil palm shell (OPS), in the industrial practice.

\section{OIL PALM SHELL AS AGGREGATE IN CONCRETE}

Oil palm shell (OPS) is a solid waste in the process of extracting oil from palm oil fruit (Fig. 1). Indonesia, Malaysia and Thailand are the major oil palm producing countries and they are generating about 90.5 million tons OPS annually [9]. A small portion of OPS is used as biofuel, however, the huge amount of this material dumped in the landfills (Fig. 2).

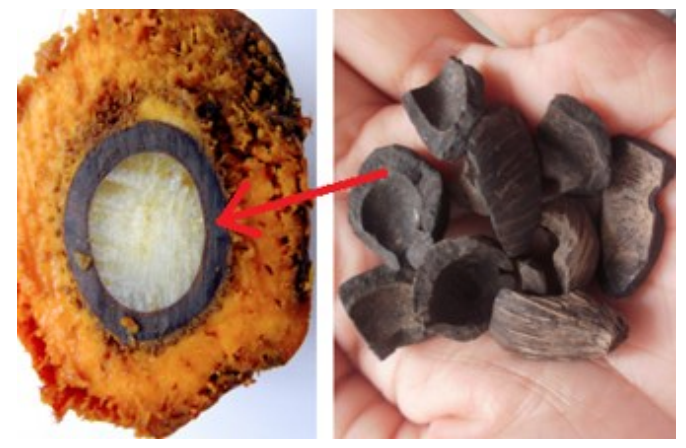

Fig. 1. Oil palm shell aggregate

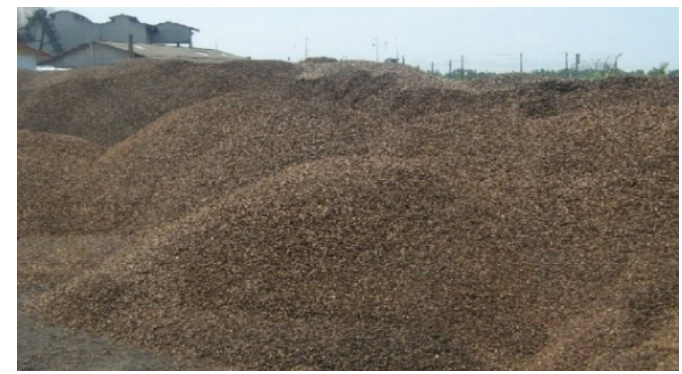

Fig. 2. Oil palm shell in palm oil mill area.
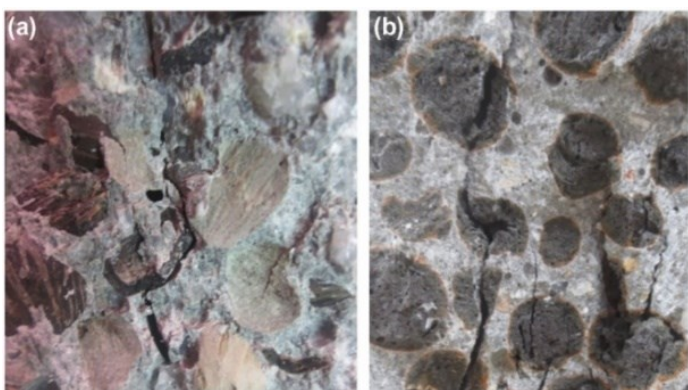

Fig 3. (a) Oil palm shell concrete, (b) Expanded clay lightweight concrete [10].
The OPS is approximately $50 \%$ lighter than conventional aggregates. It has all the requirements to be considered as a lightweight aggregate. The Los Angeles abrasion, impact and crushing values of OPS is significantly better than normal aggregate. The properties of OPS aggregates show that this aggregate has a good absorbance to the shock loads [9]. OPS is mostly available in coarse aggregate sizes. Compared to artificial lightweight aggregates, OPS is very strong and is not easy to be crushed. Fig. 3 shows crack pattern of OPS concrete (a) and lightweight expanded clay aggregate (LECA) concrete (b) after failure in compression test. As can be seen in this figure, unlike OPS, crack was passed through the LECA aggregates. It show that the strength of OPS aggregates is very high in comparing to the artificial lightweight aggregate.

However, reports on water absorption of OPS aggregates showed that this natural lightweight aggregate has relatively high water absorption compared to structural lightweight aggregate. A water absorption of about $20 \%, 10 \%$ and $8 \%$ for 24 hours, 30 minutes and 10 minutes was reported for OPS aggregates, respectively [10].

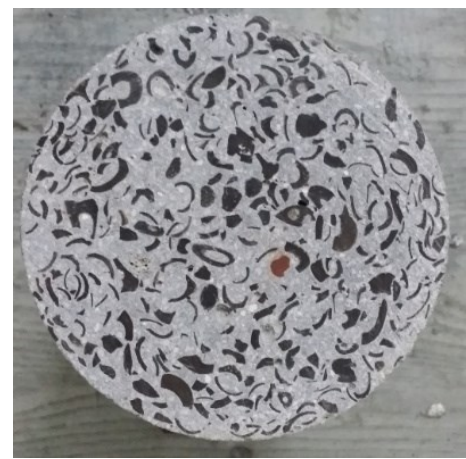

Fig. 4. Oil palm shell aggregates in concrete.

Research on the use of OPS as aggregate in concrete was started since three decades ago and is still ongoing. Fig. 4 shows a cross-section of a cylindrical concrete specimen containing OPS as coarse aggregate. The OPS aggregates are black color in this figure.

\section{PROPERTIES OF OIL PALM SHELL CONCRETES AND SOME CONCERNS}

There are many reports to prove that it is possible to produce different grades of structural lightweight aggregate concrete using OPS as the coarse aggregate with a normal range of compressive strength of 20 to $35 \mathrm{MPa}$ and a density between 20 to $25 \%$ less than conventional aggregate concrete [9]. However, OPS lightweight concrete with a high strength up to $53 \mathrm{MPa}$ at 28 days and a dry density less than $2000 \mathrm{~kg} / \mathrm{m}^{3}$ could be produced [11].

Durability performances of different grades of OPS concretes in terms of water absorption, rapid chloride penetration test, drying shrinkage and resistance to sulfate attack was investigated. In general, the reported data show that all grades of OPS concrete may not be suitable to be used in constructing structural members even its mechanical 
properties passed the structural requirements. For example, a report revealed that an OPS concrete with a 28-day compressive strength of $40 \mathrm{MPa}$ has high initial and final water absorptions, which cannot be categorized it as good concrete [12].

There was also aware of using high volume OPS aggregates in concrete mixtures. A recent study [13] on the mechanical and durability properties (in terms of water absorptions and drying shrinkage) of OPS concrete concluded that the volume of coarse OPS aggregate in the concrete mixture should not exceed from $60 \%$ of total volume of coarse aggregate. This limitation is due to the fact that concrete containing more than $60 \%$ OPS aggregates showed high drying shrinkage.

Engineers are always concerned about the durability and long-term functionality of materials during the design stage. Therefore, they should be confident to select a construction material for a specific project. Regarding durability properties of OPS concrete, there are many researches in the lab scale and there is not any report to assess the performance of this concrete in a real life. The only real structures constructed with OPS concrete are a 2 meters span footbridge in 2001 and a house with a floor area of about $59 \mathrm{~m}^{2}$ in 2003, both are located in the Universiti Malaysia Sabah (UMS) as can be seen in Fig. 5 [14]. There is not any available condition assessment report for these two structures.
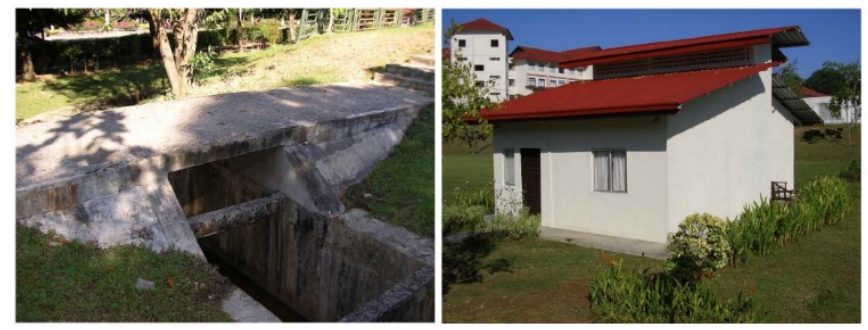

Fig. 5. Oil palm shell concrete used in a footbridge and a small house [14].

Fig. 6 shows precast concrete slabs on the ground. It is clear in this Figure that OPS aggregates on the surface of the slabs are exposed and it is expected that they will be separated from the concrete surface after sometimes. As not being durable, these slabs may need to be replaced with a new concrete slab. A reason that can explain about the condition of these slabs is due to the concave and convex faces of an original OPS aggregate are fairly smooth which cause a weak bonding between the OPS and the cement matrix [10,11].

Although, splitting tensile and flexural strengths of structural grades of OPS concrete are in the acceptable range for structural application, however, modulus of elasticity of this concrete is significantly less than conventional aggregate concrete at the same strength. A comparison between modulus of elasticity of OPS concrete reported with Hamada et al. [8] and the values given for different strength classes of normal concrete in Eurocode 2 [15] shows that OPS concretes have 50 to $60 \%$ lower modulus of elasticity.

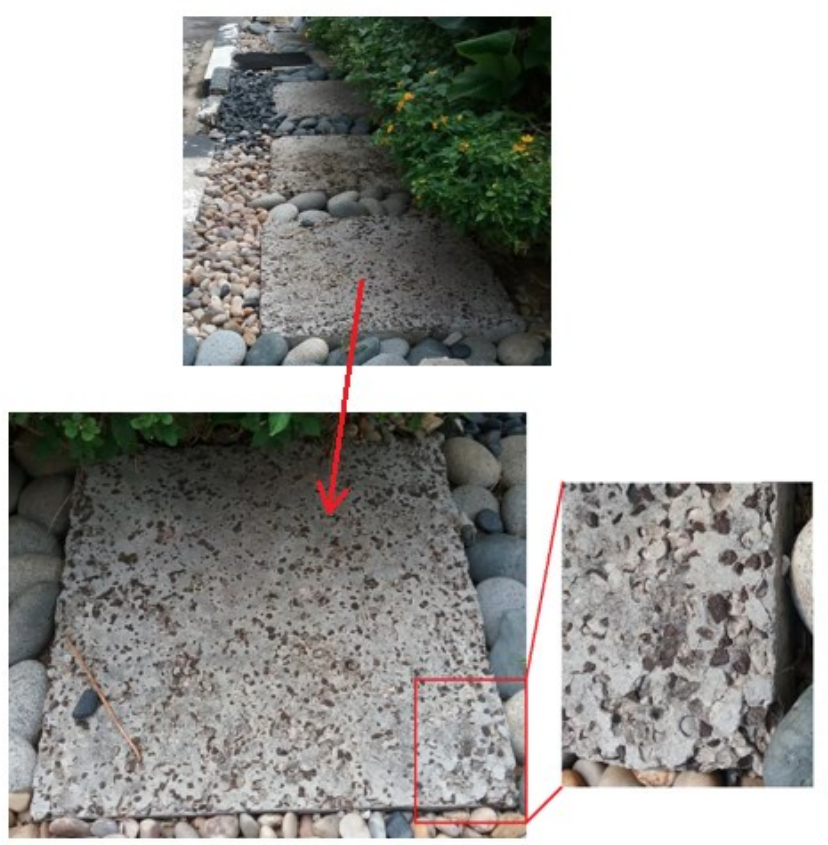

Fig. 6. Oil palm shell concrete slab

Teo et al. [16] investigated flexural behaviour of singly and doubly reinforced concrete beams produced by OPS lightweight aggregate concrete. The used OPS concrete had an average air-dry density, compressive strength, splitting tensile strength, flexural strength and modulus of elasticity of about $1950 \mathrm{~kg} / \mathrm{m}^{3}, 26 \mathrm{MPa}, 1.8 \mathrm{MPa}, 4.9 \mathrm{MPa}$ and very low modulus of elasticity of $5.2 \mathrm{GPa}$, respectively. They reported that OPS reinforced concrete beams showed typical structural behaviour. However, the deflection under the design service loads for doubly reinforced concrete beams exceeded the limit provided by BS 8110 . To overcome this drawback, they recommended that the beam depth should be increased.

Vandanapu and Krishnamurthy [17] have studied the seismic performance of a six-storied reinforced concrete framed structure using a structural grade of lightweight concrete with a modulus of elasticity of $16 \mathrm{GPa}$ and also normal concrete with a modulus of elasticity of $27 \mathrm{GPa}$. They reported that the bending moment and shear force of the members were reduced to 15 and $20 \%$, respectively, when lightweight concrete was used instead of normal-weight concrete in the structure. In addition, due to the reduction of dead load in lightweight concrete structure, there was a reduction in the area of steel of about $10 \%-12 \%$. The results of this study also showed that the displacement of the floors in lightweight concrete structure is more than normal concrete structure. They concluded that this is due to the lower modulus of elasticity of lightweight concrete compared to normal concrete. The lower modulus of elasticity results the lower stiffness for the structural members. From this study, it can be concluded that the modulus of elasticity of lightweight aggregate concrete is the most important mechanical property which was ignored in many researchers. Therefore, it is always essential to measure modulus of elasticity of bioaggregate based concretes and consider multi factors before claiming that the developed concrete mix is categorized as structural material. 


\section{REMAINING QUESTIONS ABOUT OIL PALM SHELL CONCRETE}

After extensive researches on OPS concrete, there are still other concerns, which need to be considered before applying this concrete in civil engineering projects. There is not information about fire resistant of OPS concretes. Fire resistant could be considered as a major concern due to: 1) The OPS aggregates are used as a portion of biofuel in palm oil mills, which showing that it can be burnt. How about OPS concrete? Does it possible OPS concrete burn? After exposing to high temperature in any fire accident, how much the mechanical and durability properties will be changed? There are not sufficient data to answer these questions. 2) During the burning of OPS aggregates a dark smoke is rising. Although, OPS aggregates are surrounded by cement matrix, however, the possibility of rising smoke and toxic gases should be investigated to assess the performance of OPS concrete in fire.

Although, there are several studies about drying shrinkage of OPS concrete, however, as far as the authors' knowledge, there is not information about the creep behaviour of OPS concretes. Information and analysis of creep of OPS concretes are important due to creep increases the deflection of reinforced concrete beams by time. Ahmed and Sobuz [18] reported that both creep and shrinkage are responsible for the long-term deflection of reinforced concrete beam. As the type and volume fractions of aggregates influence creep behaviour of concrete, and due to OPS is a bio-based material, it is a need to investigate creep behaviour of OPS concretes before using it in the real construction. Furthermore, for designing and analyzing of concrete structural elements, factors such as Poisson's ratio and shear modulus of different grades of OPS concretes should be studied.

\section{CONCLUSION}

Although, there are many researchers and reports about physical, mechanical, structural and durability properties of different grades of oil palm shell (OPS) concretes, however, there is still hesitation among civil engineers to consider it as structural material in their design and apply it in the practice. The existing information about OPS concretes show that this natural lightweight aggregate cannot be used fully as coarse aggregate in a concrete mixture. There are still serious issues about this concrete, which should be further investigated such as its low modulus of elasticity, behaviour in fire, creep and time-dependent deformation properties.

\section{REFERENCES}

[1] P.K. Mehta, and P.J. Monteiro, "Concrete: microstructure, properties, and materials," McGraw-Hill New York, 2006.

[2] V. Cecconello, B. R. C. Sartori, M. P. Kulakowski, C. S. Kazmierczak and M. Mancio, "Shrinkage and porosity in concretes produced with recycled concrete aggregate and rice husk ash," Revista IBRACON de Estruturas E Materiais, Vol. 12, No. 3, pp. 694-704, 2019.

M. L. Berndt, "Properties of sustainable concrete containing fly ash, slag and recycled concrete aggregate,"
Construction and Building Materials, Vol. 23, pp. 26062613, 2009.

[3] P. K. Mehta, "Reducing the environmental impact of concrete," Concr.. Int, Vol. 23, No.10, pp.61-66, 2001.

[4] E. Aprianti, P. Shafigh, S. Bahri and J. N. Farahani, "Supplementary cementitious materials origin from agricultural wastes - A review," Construction and Building Materials, Vol. 74, pp.176-187, 2015.

[5] V. W. Y. Tam, M. Soomro, A. C. J. "Evangelista. A review of recycled aggregate in concrete applications (2000-2017)," Construction and Building Materials, Vol. 172, pp. 272-292, 2018.

[6] Md. Safiuddin, M. Z. Jumaat, M. A. Salam, M. S. Islam and R. Hashim, "Utilization of solid wastes in construction materials," International Journal of the Physical Sciences Vol. 5, No. 13, pp. 1952-1963, 2010.

[7] P. Shafigh, H. B. Mahmud, M. Z. Jumaat, M. Zargar, "Agricultural wastes as aggregate in concrete mixtures a review," Construction and Building Materials, Vol. 53, pp. 110-117, 2014.

[8] H. M. Hamada, B. S. Thomas, B. Tayeh, F. M. Yahaya, K. Muthusamy, J. Yang, "Use of oil palm shell as an aggregate in cement concrete: A review,"Construction and Building Materials, Vol. 265, No.120357, 2020.

[9] P. Shafigh, M. Z. Jumaat and H. Mahmud, "Mix design and mechanical properties of oil palm shell lightweight aggregate concrete: A review," International Journal of the Physical Sciences, Vol. 5, No.14, pp. 2127-2134, 2010.

[10] P. Shafigh, H. Ghafari, H. B. Mahmud, M. Z. Jumaat, “A comparison study of the mechanical properties and drying shrinkage of oil palm shell and expanded clay lightweight aggregate concretes," Materials and Design, Vol. 60, pp. 320-327, 2014.

[11] P. Shafigh, M. Z. Jumaat, H. B. Mahmud, U. J. Alengaram, "A new method of producing high strength oil palm shell lightweight concrete," Materials and Design, Vol. 32, pp. 4839-4843, 2011.

[12] M. Maghfouri, P. Shafigh, Z. Binti Ibrahim, and V. Alimohammadi, "Quality control of lightweight aggregate concrete based on initial and final water absorption tests," IOP Conference Series: Materials Science and Engineering, Vol. 210, No. 1, article 012022, 2017.

[13] M. Maghfouri, P. Shafigh, M. Aslam, "Optimum oil palm shell content as coarse aggregate in concrete based on mechanical and durability properties," Advances in Materials Science and Engineering, Vol. 2018, Article ID $4271497,2018$.

[14] D. C. L. Teo, M. A. Mannan, V. J. Kurian, "Structural concrete using oil palm shell (OPS) as lightweight aggregate," Turkish Journal of Engineering and Environmental Sciences, Vol. 30, pp. 251-257, 2006.

[15] K. Krizova and R. Hela, "Evaluation of static modulus of elasticity depending on concrete compressive strength," World Acad. Sci. Eng. Technol. Int. J. Civ. Environ. Eng., Vol. 9, pp. 654-657, 2015.

[16] D. C. L. Teo, M. A. Mannan, V. J. Kurian, "Flexural behaviour of reinforced lightweight concrete beams made with oil palm shell (OPS)," Journal of Advanced Concrete Technology, Vol. 4, No.3, pp. 459-68, 2006.

[17] S. N. Vandanapu and M. Krishnamurthy, "Seismic performance of lightweight concrete structures," Advances in Civil Engineering, Vol. 2018, Article ID $2105784,2018$.

[18] E. Ahmed and H. R. Sobuz, "Flexural and timedependent performance of palm shell aggregate concrete beam," KSCE Journal of Civil Engineering, Vol. 15, No. 5, pp.859-865, 2011. 